\title{
Relationship between Surface Polarity and Moisture Control onto Carbonaceous Materials Produced from Bean Curd Lees
}

\author{
Ryoma Bun-ei, Naohito Kawasaki *, Takeo Nakamura, Fumihiko Ogata \\ and Seiki TANADA \\ School of Pharmaceutical Sciences, Kinki University \\ (3-4-1, Kowakae, Higashi-Osaka, Osaka 577-8502, JAPAN)
}

Edited by T. Tamura, Lion Corp., and accepted September 13, 2005 (received for review August 4, 2005)

\begin{abstract}
In order to promote the shift to zero emissions of organic wastes, it is necessary to create carbon cycling processes. On the other hand, one of the distinguishing features of the Japanese climate is its high humidity, and an adsorbent which is high ability of moisture control are needed to prevent putrefaction of wood and keep indoor spaces at a comfortable humidity. This research focused on producing a carbonaceous material produced from bean curd lees, which is a form of food waste, and studied the relationship between the surface polarity or specific surface area of carbonaceous material, and the ability of moisture control. The specific surface area of the carbonaceous material was measured, and the highest value was exhibited in carbonaceous material produced at a temperature of $1173 \mathrm{~K}$. From this result, it appears that a microstructure develops as the carbonization temperature increases, but when the carbonization temperature is increased further, the specific surface area decreases due to merging of pores. Also, the ability of moisture control of charcoal is 22 , and the ability of moisture control of the carbonaceous material produced from bean curd lees is a maximum of 198. This suggests that the material can be used in applications as a moisture control material. This work clarified that the ability of moisture control of the carbonaceous material increases to the degree that there are fewer phenolic hydroxyl groups and carboxyl groups in the carbonaceous material surface.
\end{abstract}

Key words: moisture control, bean curd lees, carbonaceous material, polarity group

\section{Introduction}

In recent years, increasing priority has been placed on the concept of "zero emissions", where wastes are recycled and effectively used. However, in order to further promote zero emissions, it is necessary to create carbon cycling processes (1-3). If waste is converted to carbonaceous material, it is possible to reduce atmospheric emissions of carbon dioxide equivalent to the carbon content in the carbonaceous material. It is desirable for a carbonaceous material made from organic waste to have greater functionality -- i.e. the ability of moisture control superior to previous materials. Also, carbonaceous material which is produced at a lower carbonization temperature will be a less expensive carbon material. The recycling of coffee grounds by carbonization was reported (4-8). We reported the adsorption characterization of water onto carbonaceous materials produced from coffee grounds and oolong tea leafs as vegetable biomass (9).

Activated carbon has been used as an adsorbent in various industrial fields, including solvent recovery, gas separation, catalysts, deodorization, and moisture control $(10,11)$. Moisture control adsorbents are common-

\footnotetext{
*Correspondence to: Naohito KAWASAKI, School of Pharmaceutical Sciences, Kinki University, 3-4-1, Kowakae, Higashi-Osaka, Osaka 5778502, JAPAN

E-mail: kawasaki@phar.kindai.ac.jp
} 
ly used in Japan due to the high humidity, and charcoal has previously been used for this purpose. Excessive humidity causes condensation, mildew and outbreaks of mites. Rotting of the wood parts of foundations also causes deterioration of homes. Therefore, in Japan it is crucial to develop the adsorbents, which is high ability of moisture humidity, to remove excess moisture and maintain comfortable humidity. By maintaining a comfortable humidity, it is possible to control outbreaks of mildew and mites, and thus prevent allergies and save air-conditioning costs by making the summer cooler and the winter warmer, thereby contributing to energy conservation. Furthermore, comfortable humidity levels have recognized effects in promoting the health of people, i.e. by promoting metabolism and sound sleep, making the body feel lighter, and facilitating quick recovery from fatigue.

In this study, bean curd lees (a food waste) was carbonized at different temperatures, and the relationship between its surface polarity or specific surface area, and the ability of moisture control, was evaluated and studied.

\section{Experimental and Method}

\subsection{Materials}

The bean curd lees used is dried at $383 \mathrm{~K}$ for $15 \mathrm{~h}$ and the composition is For the carbonization, $10 \mathrm{~g}$ of dried commercial bean curd lees was placed in a porcelain crucible, and kept at $773-1373 \mathrm{~K}$ for $2 \mathrm{~h}$ in a muffle furnace, which was heated at a speed of $5 \mathrm{~K} / \mathrm{min}$. Charcoal was gone into commercial production and was produced from Quercus phillyraeoides. The specific surface area of the carbonaceous materials was found using BELSORP 40A (BEL JAPAN, INC., Osaka, Japan), that is, the specific surface area of the carbonaceous materials was calculated according to the nitrogen adsorption onto the carbonaceous materials was fitted to BET equation. Measurement of the surface $\mathrm{pH}$ of the carbonaceous materials was done using the method of Urano et al.(12) Carbonaceous material (0.5 g) was placed in an Erlenmeyer flask, and $100 \mathrm{~mL}$ of purified water was added. After boiling for 5 minutes, the fluid was cooled to room temperature, and the $\mathrm{pH}$ of the filtrate was measured using a HORIBA F-11 glass electrode type hydrogen ion concentration meter (HORIBA, Ltd., Kyoto, Japan)

\subsection{Amount of Water Adsorbed/Desorbed onto Carbonaceous Materials}

Carbonaceous materials $(0.3 \mathrm{~g})$ were measured in a weighing bottle, and left for $24 \mathrm{~h}$ in a desiccator kept at $293 \mathrm{~K}$ with fixed humidity in Table 1. We confirmed that the water sorption onto the carbonaceous materials reached to equilibrium for $15 \mathrm{~h}$. Then the weight of carbonaceous materials before and after adsorption was measured, and the amount of water adsorbed was calculated from the difference.

The saturated amount of adsorbed was calculated in a similar way, by leaving for $24 \mathrm{~h}$ in a desiccator kept at $293 \mathrm{~K}$ and a relative humidity of $100 \%$. To determine the amount of water desorbed, carbonaceous materials was placed in the saturation adsorption state at $293 \mathrm{~K}$ and relative humidity of $100 \%$, and the weight was measured, and then was kept in a desiccator, which the relative humidity was lowered to $95 \%, 84 \%, 78 \%, 66 \%$, $52 \%, 42 \%, 32 \%, 20 \%$ and $15 \%$. The desorption isotherm was calculated from the weight before and after desorption. For comparison, measurements were also done under the same conditions using charcoal produced from Quercus phillyraeoides. The difference between the amount of water adsorbed at a relative humidity of $100 \%$ and the amount of water adsorbed at a relative humidity of $52 \%$ was taken to be the ability of moisture control.

\subsection{Base Consumption of Carbonaceous Materials}

Base consumption of carbonaceous materials was measured using the methods of Boehm and Voll (13, 14). That is, the base consumption was found by adding approximately $0.1 \mathrm{~g}$ of carbonaceous materials to $50 \mathrm{ml}$

Table 1 Moisture Control by Materials.

\begin{tabular}{lc}
\hline \multicolumn{1}{c}{ Materials } & Relative humidity (\%) \\
\hline $\mathrm{LiCl} \cdot \mathrm{H}_{2} \mathrm{O}$ & 15 \\
$\mathrm{CH}_{3} \mathrm{COOK}$ & 20 \\
$\mathrm{CaCl}_{2} \cdot 6 \mathrm{H}_{2} \mathrm{O}$ & 32 \\
$\mathrm{Zn}\left(\mathrm{NO}_{3}\right)_{2} \cdot 6 \mathrm{H}_{2} \mathrm{O}$ & 42 \\
$\mathrm{NaHSO}_{4} \cdot \mathrm{H}_{2} \mathrm{O}$ & 52 \\
$\mathrm{NaNO}_{2}$ & 66 \\
$\mathrm{Na}_{2} \mathrm{~S}_{2} \mathrm{O}_{3} \cdot 5 \mathrm{H}_{2} \mathrm{O}$ & 78 \\
$\mathrm{KBr}$ & 84 \\
$\mathrm{Na}_{2} \mathrm{HPO}_{4} \cdot 12 \mathrm{H}_{2} \mathrm{O}$ & 95 \\
\hline
\end{tabular}


of $0.1 \mathrm{~mol} / \mathrm{L}$ sodium hydroxide aqueous solution (Wako Pure Chemical Co., Ltd., Osaka, Japan), shaking for 48 $\mathrm{h}$ at $298 \mathrm{~K}$, filtering and then titrating the filtrate with $0.1 \mathrm{~mol} / \mathrm{L}$ sodium hydroxide aqueous solution (Wako Pure Chemical Co., Ltd., Osaka, Japan). Methyl red was used as the indicator.

\section{Results}

\subsection{Physical Properties of Carbonaceous Materials}

Table 2 shows the specific surface area, the pore volume, surface $\mathrm{pH}$ and the base consumption for carbonaceous materials. The results indicate that the specific surface area of carbonaceous material produced at $973 \mathrm{~K}$ or less was extremely low, but even though there was an increase in specific surface area of carbonaceous material produced at $1173 \mathrm{~K}$ or higher, there was a decrease in the specific surface area of carbonaceous material produced at $1273 \mathrm{~K}$ or higher. The pore volume of the carbonaceous material is correlated to the specific surface area of them. The surface $\mathrm{pH}$ value was in the range 9.1 to 10.1 , and the $\mathrm{pH}$ value rose to the degree that the carbonaceous material was produced at a higher temperature. Base consumption is measured the number of functional groups on the carbonaceous material surface, and corresponds in particular to phenolic hydroxyl and carboxyl groups $(13,14)$. In terms of base consumption, a declining trend was evident in carbonaceous materials made at higher temperatures, and for carbonaceous material produced at a temperature of $1173 \mathrm{~K}$ or higher, the value became negative. Therefore, it is thought that the surface polarity of carbonaceous material decreases when the material is produced at higher carbonization temperature. Base consumption of some carbonaceous materials was negative value because bean curd lees contain much protein, many kinds of basic amino acids.

\section{$3 \cdot 2$ Adsorption/Desorption Isotherms of Water onto Carbonaceous Material}

Figure 1 shows the adsorption/desorption isotherms of water onto carbonaceous materials. In the results, a sudden increase in the amount of water adsorbed to charcoal was evident for relative humidities of $0-50 \%$, but no increase in the amount of water adsorbed was seen for relative humidities of $50-100 \%$. On the other hand, the amount of water desorbed onto charcoal was almost the same as the amount of water adsorbed for relative humidities of $60-100 \%$, and hysteresis was evi-

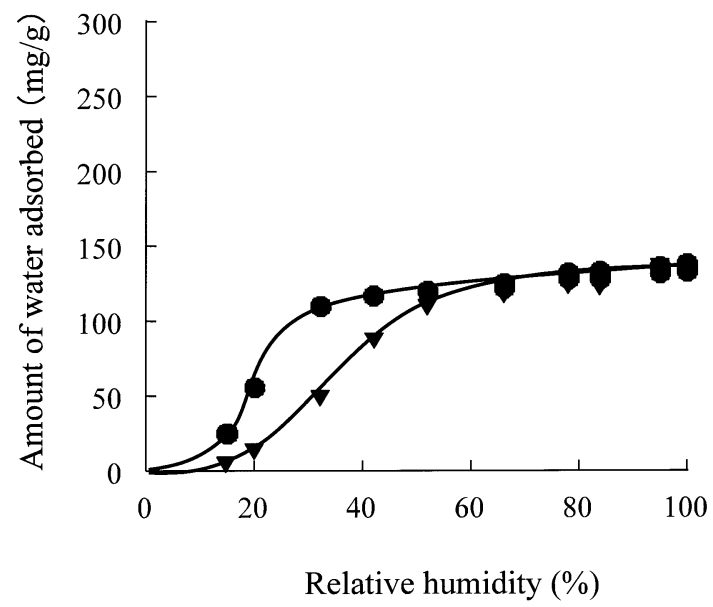

Fig. 1 Adsorption/Desorption Isotherms of Water onto Charcoal.

$\boldsymbol{\nabla}$ : Adsorption, $\mathbf{O}$ : Desorption

Table 2 Physical and Chemical Properties of Carbonaceous Materials.

\begin{tabular}{ccccc}
\hline Samples & $\begin{array}{c}\text { Specific surface } \\
\text { area }\left(\mathrm{m}^{2} / \mathrm{g}\right)\end{array}$ & $\begin{array}{c}\text { Pore volume } \\
(\mathrm{mL} / \mathrm{g})\end{array}$ & $\begin{array}{c}\text { Surface } \\
\mathrm{pH}\end{array}$ & $\begin{array}{c}\text { Base consumption } \\
(\mathrm{mmol} / \mathrm{g})\end{array}$ \\
\hline $773 \mathrm{~K}$ & 1.9 & 0.006 & 9.1 & 0.012 \\
$873 \mathrm{~K}$ & 1.9 & 0.006 & 9.7 & 0.012 \\
$973 \mathrm{~K}$ & 3.3 & 0.008 & 9.7 & 0.009 \\
$1073 \mathrm{~K}$ & 44.7 & 0.022 & 9.8 & 0.003 \\
$1173 \mathrm{~K}$ & 67.0 & 0.032 & 10.1 & -0.016 \\
$1273 \mathrm{~K}$ & 11.0 & 0.015 & 9.6 & -0.035 \\
$1373 \mathrm{~K}$ & 7.8 & 0.011 & 10.1 & -0.023 \\
Char & 35.0 & 0.116 & 6.8 & 0.016 \\
\hline
\end{tabular}


dent in the range $0-60 \%$.

Figure 2 shows the adsorption/desorption isotherms of water onto carbonaceous material, which is produced from bean curd lees at $773 \mathrm{~K}$. In the results, the adsorption isotherm has an "S" shape, and the amount of water adsorbed exhibited a lower value than the amount of water desorbed over the entire humidity range. Also, the amount of water adsorbed/desorbed onto the carbonaceous materials, which were produced from bean curd lees, exhibited a higher value than that of water onto charcoal. On the other hand, hysteresis was evi-

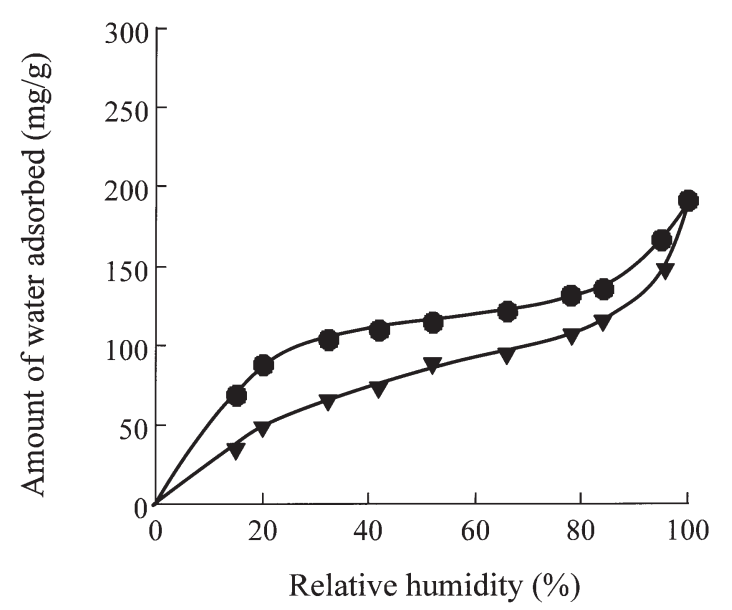

Fig. 2 Adsorption/Desorption Isotherms of Water onto Carbonaceous Material, which was Produced from Bean Curd Lees at 773K.

$\nabla$ : Adsorption, $\mathrm{O}$ : Desorption

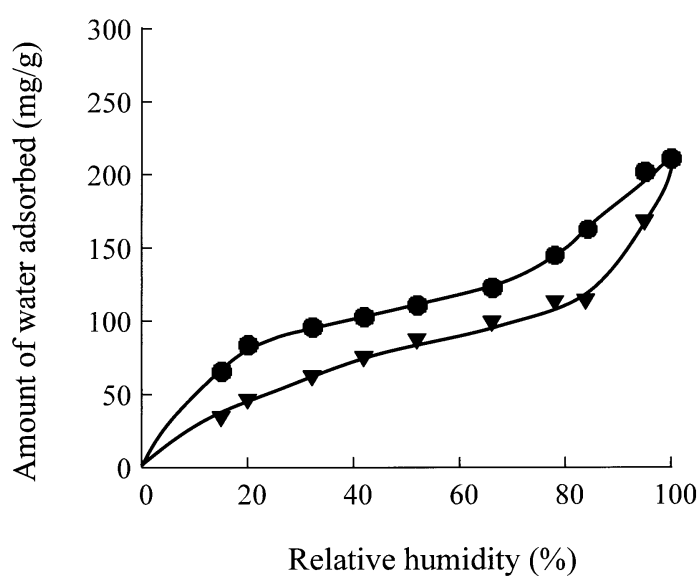

Fig. 3 Adsorption Desorption Isotherms of Water onto Carbonaceous Material, which was Produced from Bean Curd Lees at $873 \mathrm{~K}$.

$\nabla$ : Adsorption, $\mathrm{O}$ : Desorption dent over the entire relative humidity range, and it was found that desorption by the carbonaceous materials, which were produced from bean curd lees, was more difficult after water adsorption.

Figures 3-5 show the adsorption/desorption isotherms of water onto the carbonaceous materials, which are produced from bean curd lees at 873 to $1073 \mathrm{~K}$. In the results, the amount adsorbed gradually increases just as with carbonaceous material, which is produced at $773 \mathrm{~K}$ in the low relative humidity range. Also, the amount of water adsorbed onto the carbona-

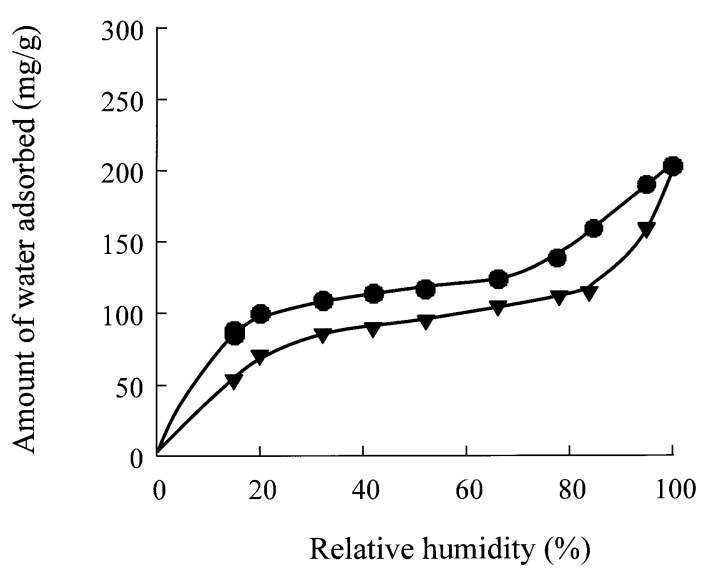

Fig. 4 Adsorption/Desorption Isotherms of Water onto Carbonaceous Material, which was Produced from Bean Curd Lees at 973K.

$\boldsymbol{\nabla}$ : Adsorption, $\mathrm{O}$ : Desorption

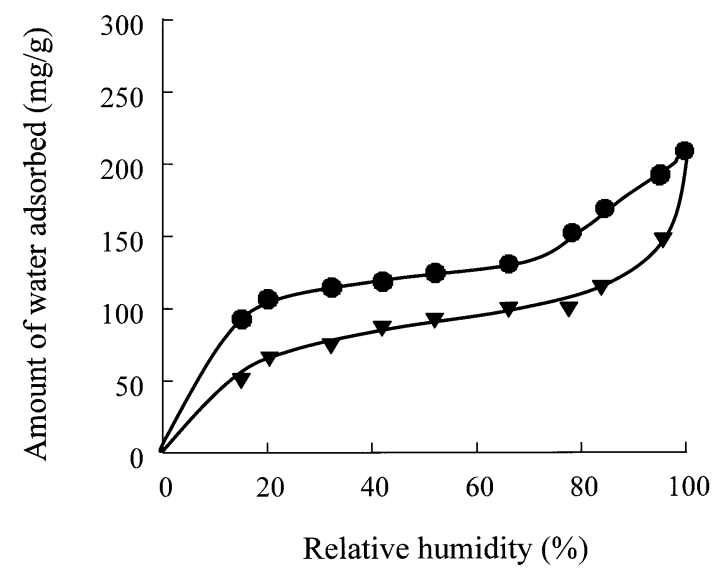

Fig. 5 Adsorption/Desorption Isotherms of Water onto Carbonaceous Material, which was Produced from Bean Curd Lees at 1073K.

$\boldsymbol{\nabla}$ : Adsorption, $\mathrm{O}$ : Desorption 
ceous material, which is produced from bean curd lees at $873 \mathrm{~K}$ and $973 \mathrm{~K}$, increases and the amount of water desorbed decreases, compared to carbonaceous material, which was produced at $773 \mathrm{~K}$ with relative humidity of $70 \%$ or more, and the hysteresis was larger than that of charcoal and carbonaceous material, which was produced at $773 \mathrm{~K}$.

Figures 6-8 show the adsorption/desorption isotherms of water onto the carbonaceous material, which is produced from bean curd lees at 1173 to $1373 \mathrm{~K}$. In the results, the adsorption isotherm of water

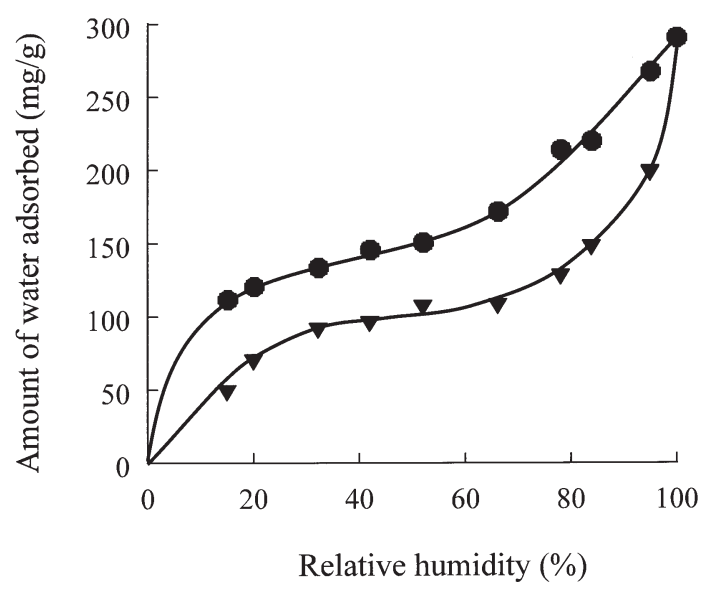

Fig. 6 Adsorption/Desorption Isotherms of Water onto Carbonaceous Material, which was Produced from Bean Curd Lees at $1173 \mathrm{~K}$.

$\nabla$ : Adsorption, $\mathrm{O}$ : Desorption

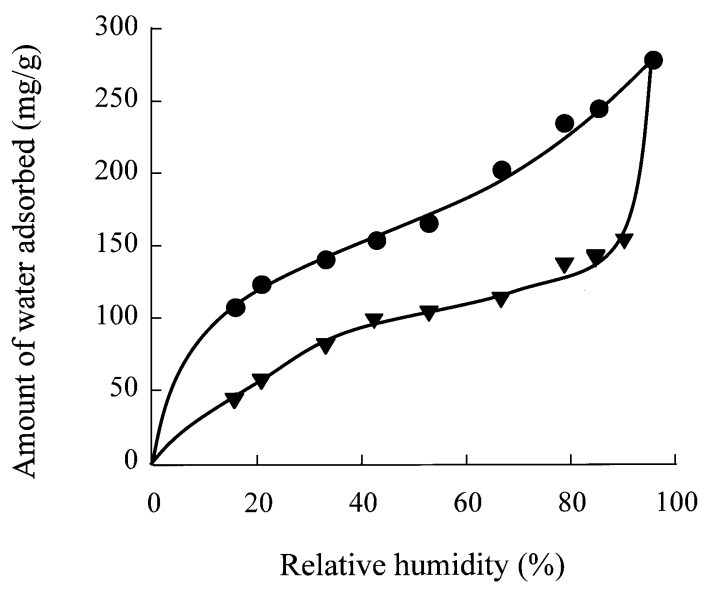

Fig. 7 Adsorption/Desorption Isotherms of Water onto Carbonaceous Material, which was Produced from Bean Curd Lees at $1273 \mathrm{~K}$.

$\nabla$ : Adsorption, $\mathrm{O}$ : Desorption has an " $\mathrm{S}$ " shape, and, more specifically, there is a sudden increase in the amount of water adsorbed near the saturated relative humidity. On the other hand, hysteresis is evident in the entire relative humidity range.

\section{3·3 Ability of Moisture Control of Car- bonaceous Material Produced from Bean Curd Lees}

Table 3 shows the ability of moisture control of charcoal and carbonaceous material, which is produced from bean curd lees. The results show that the ability of moisture control of carbonaceous material, which was produced from bean curd lees, was higher than that of charcoal.

Figure 9 shows the relationship between base consumption and the ability of moisture control by carbonaceous materials which were produced from bean curd lees. In the results, a negative correlation with a correlation coefficient of 0.966 [(base consumption $)=$ -0.000408 (ability of control humidity) +0.05172$]$ was evident between base consumption and the ability of moisture control.

\section{Discussion}

The specific surface area of the carbonaceous material was measured, and the highest value was exhibited in carbonaceous material, which was produced at a temperature of $1173 \mathrm{~K}$. From this result, it appears that a microstructure develops as the carbonization tempera-

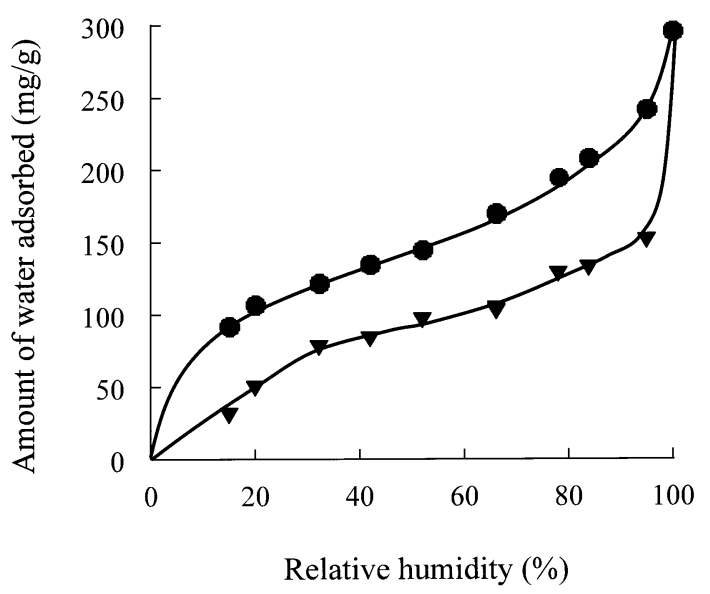

Fig. 8 Adsorption/Desorption Isotherms of Water onto Carbonaceous Material, which was Produced from Bean Curd Lees at $1373 \mathrm{~K}$.

$\boldsymbol{\nabla}$ : Adsorption, $\mathrm{O}$ : Desorption 
R. Bun-ei, N. Kawasaki, T. Nakamura et al.

Table 3 Ability of Moisture Control of Carbonaceous Materials.

\begin{tabular}{cccc}
\hline \multirow{2}{*}{ Samples } & \multicolumn{3}{c}{ Amount of water adsorbed (mg/g) } \\
\cline { 2 - 4 } & at relative humidity $100 \%$ & at relative humidity 52\% & Moisture control (\%) ${ }^{\text {a) }}$ \\
\hline $773 \mathrm{~K}$ & 191 & 93 & 98 \\
$873 \mathrm{~K}$ & 211 & 97 & 114 \\
$973 \mathrm{~K}$ & 203 & 99 & 104 \\
$1073 \mathrm{~K}$ & 204 & 101 & 103 \\
$1173 \mathrm{~K}$ & 291 & 120 & 171 \\
$1273 \mathrm{~K}$ & 312 & 114 & 198 \\
$1373 \mathrm{~K}$ & 296 & 103 & 22 \\
Char & 136 & 113 & 22 \\
\hline
\end{tabular}

a) (Amount of water adsorbed at relative humidity 100\%) - (Amount of water adsorbed at relative humidity $52 \%$ )

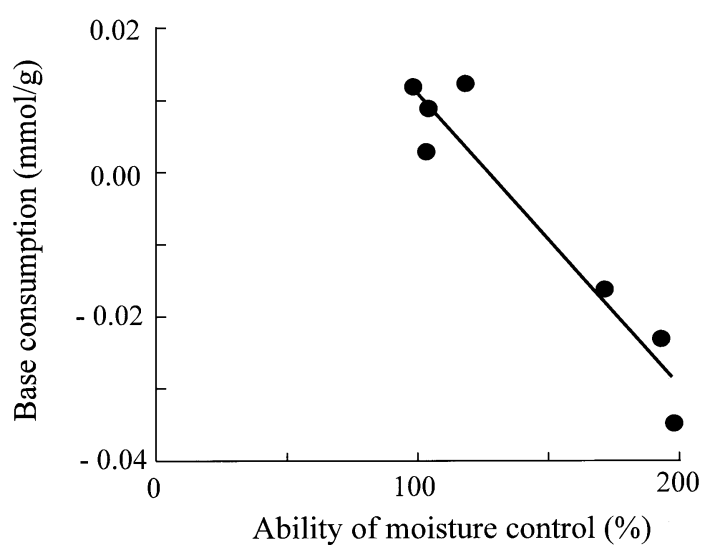

Fig. 9 Relationship between Base Consumption and Ability of Moisture Control Humidity.

ture increases, but when the carbonization temperature is increased further, the specific surface area decreases due to merging of pores. From the results on the adsorption isotherms of water onto carbonaceous materials, which were produced in the range 773 to $1373 \mathrm{~K}$, it was found that adsorption behavior is almost the same, but the saturated amount of water adsorbed increases together with the carbonization temperature. On the other hand, it became clear that the hysteresis onto carbonaceous materials, which are produced at a higher carbonization temperature, is large, and thus it is difficult to desorb water molecules which have been adsorbed.

The ability of moisture control of carbonaceous material, which was produced from bean curd lees, was higher than that of charcoal. No relationship was evident between the specific surface area and the ability of moisture control of the carbonaceous material. The ability of moisture control of the carbonaceous materials, which were produced from bean curd lees, was 4.59.0 times that of charcoal. More specifically, the ability of moisture control was greater for materials with smaller base consumption, and carbonacaeous material, which was produced at $773 \mathrm{~K}$, exhibited the ability of moisture control approximately 4.5 times that of charcoal.

The relationship between base consumption and the ability of moisture control was a negative correlation (a correlation coefficient is 0.966 ). This suggests that reduction of phenolic hydroxyl groups and carboxyl groups in the surface increases the ability of moisture control. It has been reported that phenolic hydroxyl groups and carboxyl groups form hydrogen bonds with water molecules, and that the bonding strength is 5-10 times that of the Van der Waals strength (15). This result is thought to be because it is difficult to desorb water molecules which have been adsorbed if there are polar groups present in the carbonaceous material surface.

\section{Conclusions}

This paper studied the relationship between surface polarity and moisture control performance of the carbonaceous materials, which were produced from bean curd lees at different carbonization temperatures. The research clarified that the bond strength between water molecules and polar groups in the carbonaceous material surface increases and the ability of moisture control decreases as the number of phenolic hydroxyl and carboxyl groups in the surface increases. Also, it is possible to make carbonaceous materials with high ability of 
moisture control by carbonization of bean curd lees, which is an organic waste.

\section{References}

1. M. MAEDA and T. IKEDA, Recycling and Material Flow of the World, Polymers for Advanced Technologies, Vol. 11, 388-391 (2000).

2. G. PAULI, How to Compete in the $21^{\text {st }}$ Century-Bold Ideas and Concrete Applications-Tha Case of Zero Emissions, Chem. Enginer. World, Vol. 32, 81-86 (1997).

3. G. PAULI, Zero Emissions Research Initiative. How to Complete in the Future?, Sangyo to Kankyo, Vol. 36, 107-120 (1997).

4. M. HIRATA, N. KAWASAKI, T. NAKAMURA, R. BUNEI and S. TANADA, Removal of Formaldehyde by Surface-Modified Carbonaceous Materials, Hyomen Kagaku, Vol. 24, 417-422 (2003).

5. M. HIRATA, N. KAWASAKI, T. NAKAMURA, K. MATSUMOTO, M. KABAYAMA, T. TAMURA and S. TANADA, Adsorption of Dyes onto Carbonaceous Materials Produced from Coffee Grounds by Microwave Treatment, J. Colloid Interface Sci., Vol. 254, 17-22 (2002).

6. Y. ARAI, S. UEDA and Y. ISHII, Continuous Carbonization Apparatus Consisting of Carbonization Furnace and Combustion Furnace, Japan Pat., 136390 (2000).

7. T. OCHI, N. TAKEUCHI, N. SATO, T. OHIZUMI and T. OHKI, Sebun Absorbent Paper Containing Sasa Components and/or Plant Fiber Carbonized Products with Antimicrobial and Deodorant Effect, Japan Pat., 287731 (2000).

8. D. KATAYAMA and M. KATAYAMA, Method and Apparatus for Fermentation-Drying, Preliminary Carbonizing, and Burning of Plant-Derived Organic Waste and High Temperature Fermentation Bacteria Atrain and Fermented and Dried Materials, Japan Pat., 11319789 (1999).

9. A. NAKANUSHI, M. TAMAI, N. KAWASAKI, T. NAKAMURA, M. ARAKI and S. TANADA, Characterization of Water Adsorption onto Carbonaceous Materials, J. Colloid Interface Sci., Vol. 255, 59-63 (2002).

10. S. TANADA, A. NAKANISHI, M. TAMAI, N. KAWASAKI, T. NAKAMURA, K. MATSUMOTO and M. HIRATA, In-house Moisture Control by Carbonaceous Materials Produced from Organic by-Products, Environ. Sci., Vol. 15, 131-141 (2002).

11. K. KINOSHITA, “Carbon.” Chap. 4, Wiley, New York (1988).

12. K. URANO, M. SONAI, R. NAKAYAMA and Y. KOBAYASHI, Studies on Water Treatment by Adsorption. V. Adsorption Mechanism of Strong Acids, Strong Base, or their Salts by Activated Carbon and $\mathrm{pH}$ of the Solution with Carbon Suspension, Nippon Kagaku Kaishi, Vol. 11, 1773-1778 (1976).

13. H.P. BOEHM and M. VOLL, Catalytic Hydrogen Chloride Oxidation on Carbon Black, Carbon, Vol. 8, 99 (1970).

14. H.P. BOEHM, Functional Groups on the Surface of Solids, Angew. Chem. Intern. Ed. Engl., Vol. 5, 533-544 (1966).

15. S. KONDO, T. ISHIKAWA and I. ABE, “Kyucyaku No Kagaku (Science of Adsorption)” Maruzen, Tokyo, p. 192 (1991). 